\title{
Excessive Alcohol Consumption and Violent Brawls: A Randomized Controlled Trial with Bartenders in Bogotá, Colombia *
}

\author{
Andrés Felipe Camacho ${ }^{\mathrm{a}}$, Andrés Ham ${ }^{\mathrm{b}}$, Darío Maldonado ${ }^{\mathrm{b}}$, and \\ Michael Weintraub ${ }^{\mathrm{b}}$ \\ ${ }^{\mathrm{a}}$ Fiscalía General de la Nación \\ ${ }^{\mathrm{b}}$ School of Government, Universidad de los Andes
}

Pre-Analysis Plan

March 7, 2019

\begin{abstract}
Excessive alcohol consumption tends to instigate violence, particularly in and around alcohol-serving establishments. Policies that ban or restrict alcohol have been shown to defuse violence but impose restrictions on the community and may be unenforceable in certain contexts. Fewer evidence exists regarding policies that raise awareness among bartenders and patrons of the adverse consequences of excessive alcohol consumption. This study evaluates an intervention conducted by the Bogotá mayor's office and Colombia's largest brewery to empower bartenders, provide didactic materials to bar patrons, and offer food and non-alcoholic drinks to bar patrons. The intervention has two primary objectives: i) reduce the negative consequences associated with the over-consumption of alcohol and ii) defuse conflicts between bartenders and patrons, and among patrons, that might escalate to violence within and around bars. Our unit of observation is the street segment, nested within police quadrants. We first randomize 221 police quadrants into treatment and control groups. Second, in the 109 treated quadrants, we randomly select eligible street segments with alcoholserving establishments to receive the intervention. This design captures both direct effects of the intervention on violent brawls for street segments within treated police quadrants and potential spillover effects across police quadrants.
\end{abstract}

Keywords: violence, brawls, alcohol consumption, bars.

JEL Classification: C93, D74, K42, D90.

\footnotetext{
*Contact information: Andrés Felipe Camacho, af.camacho1169@uniandes.edu.co; Andrés Ham, a.ham@uniandes.edu.co; Darío Maldonado, dmaldonadoc@uniandes.edu.co; and Michael Weintraub, ml.weintraub@uniandes.edu.co.
} 


\section{Contents}

Page

1 Motivation 3

2 Study setting $\quad 4$

3 Context: Alcohol and violent brawls in Bogotá

4 Randomization $\quad 11$

5 Intervention $\quad 16$

5.1 Contact $/$ registration $\ldots \ldots \ldots \ldots \ldots$

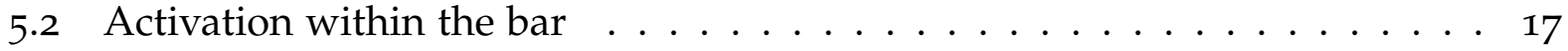

5.3 Follow-up and data collection . . . . . . . . . . . . . . . 17

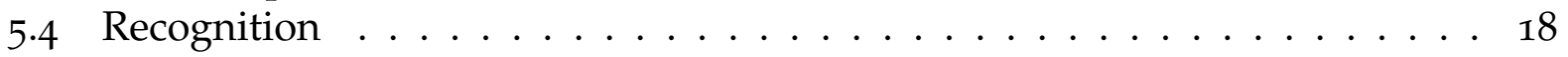

6 Theoretical framework and hypotheses $\quad 18$

7 Data $\quad 21$

8 Estimation strategy $\quad 22$

9 Threats to inference $\quad 24$

10 Conclusion $\quad 25$ 


\section{Motivation}

Excessive alcohol consumption remains a pressing concern for public policy: it is associated with a host of physical maladies, ${ }^{1}$ psychological disorders, ${ }^{2}$ as well as the commission of crimes. A recent meta-analysis (Griswold et al., 2018) found that 3 million deaths in 2016 were attributable to alcohol, not including those related to alcohol-attributable violence. ${ }^{3}$ Global alcohol-attributable violence is estimated to account for 248 ,ooo annual deaths (Graham and Livingston, 2011), and observational studies frequently find alcohol consumption to be positively correlated with homicides (Rossow, 2001). Despite existing evidence suggesting such a link, few studies use experimental methods to convincingly establish causal relationships between changes in alcohol consumption and crime.

Given the public health and security risks associated with excessive alcohol consumption, governments have often struggled to design and implement effective public policies. Governments have levied higher taxes on alcohol, raised the drinking age, imposed curfews on establishments serving alcohol, cracked down on public consumption (so-called "open container" laws), have provided fewer liquor licences to alcohol-serving establishments (and more generally limited alcohol availability), and conducted informational campaigns to expose the dangers of (over)consumption and encourage the responsible use of alcohol (Pridemore and Snowden, 2009; Lovenheim and Steefel, 2011; Heaton, 2012; Grönqvist and Niknami, 2014; Marcus and Siedler, 2015; Anderson et al., 2016). The literature has concluded that restricting alcohol availability tends to reduce interpersonal violence and the commission of crimes, but reported effects are small.

Generalized interventions to reduce consumption may be inadequate to sever the link

\footnotetext{
${ }^{1}$ Including, for example, liver cirrhosis, hypertension and stroke, cancers of the mouth, pharynx, esophagus and liver, and the proliferation of infectious disease (e.g. Room et al., 2002).

${ }^{2}$ Especially disorders of the nervous system, depression, other affective disorders, and suicide (e.g. Room et al., 2002; Sher, 2005).

${ }^{3} \mathrm{~A}$ recent study from Canada found that the country's minimum legal drinking age "reduces mortality rates of young men," with smaller effects on women.
} 
between alcohol and violence given that highly-focused interventions across a variety of policy domains - in this case targeting individuals most likely to over-consume and, even more specifically, targeting those whose over-consumption is most likely to translate into violence - show the greatest likelihood of success (e.g. Abt, 2017).4 The lack of publicprivate partnerships between state authorities and the private sector, which could help incentivize responsible consumption, also may help account for these modest results.

In this Pre-Analysis Plan we describe the proposed evaluation of a randomized controlled trial that studies the impact of an intervention directed at bartenders in four neighborhoods or localities in Bogotá, Colombia. The goal of the study is to determine whether alcohol-induced violent brawls can be reduced via a low-cost, scalable intervention undertaken through a public-private partnership. The intervention has been designed by Bogotá's mayor's office, Colombia's largest brewery (Bavaria) 5 , and the team of researchers. Its objectives are to empower bartenders, provide didactic materials to bar patrons, and offer food and non-alcoholic drinks to bar patrons. Should this intervention prove successful in reducing violence, it could be scaled up to the entire city and serve as a model for similar efforts in other cities within Colombia, as well as other countries.

\section{Study setting}

Our study focuses on the Colombian capital of Bogotá, home to more than 8 million people. The city has had historically high levels of violence. Despite recent strides in lowering violent crime rates in Bogotá and Colombia in general, violence remains common with high spatial clustering in relatively few locations (Blattman et al., 2017).

Improvements in public security can partly explain the generalized improvements in violence indicators throughout Colombia following the demobilization of the coun-

4This is equivalent to tertiary prevention strategies in public health, which target those already engaged in risky behavior, rather than either the population as a whole (primary prevention) or those who may become involved in such behavior in the future (secondary prevention).

${ }^{5}$ Bavaria was purchased by SABMiller in 2005, and later became part of Anheuser-Busch InBev. 
try's largest rebel group (FARC) via a peace agreement signed in late 2016, as well as regression-to-the-mean dynamics following a period of extreme violence during the late 1990 and early 2000 .

The intervention we study was created in response to policy demands from city authorities to design and evaluate interventions aimed at reducing violent brawls in and around establishments that serve alcohol, which have represented particular governance challenges for several city administrations. Our partners for this intervention are the Security and Justice Secretariat of the Mayor's Office of Bogotá, and Fundación Bavaria, the corporate social responsibility unit of Colombia's largest brewery.

\section{Context: Alcohol and violent brawls in Bogotá}

Given the size of the city of Bogotá, the intervention was conceived as a pilot, focusing on four localities - Fontibón, Mártires, Suba and Engativá - chosen by the Mayor's Office of Bogotá given their high concentration of alcohol-serving establishments and, in some cases, violent brawls. Figure 1 maps the location of the targeted neighborhoods. Localities are divided into police quadrants, and the latter are split into street segments.

Prior to undertaking the intervention, the research team responsible for the evaluation of the program hired anthropologists to carry out ethnographic fieldwork in the four selected localities. This qualitative work, carried out over the course of 96 hours, was intended to observe the dynamics of alcohol consumption, interactions among patrons and with bartenders, as well as the characteristics of the physical environment in randomly-selected bars within the four localities. In addition, the team interviewed 16 bartenders (4 per locality), 4 members of the police force ( 1 per locality) and members of the mayor's staff ( 2 in total) responsible for community outreach on citizen security issues. This fieldwork took place between December 2017 and January 2018. 
Figure 1. Targeted neighborhoods

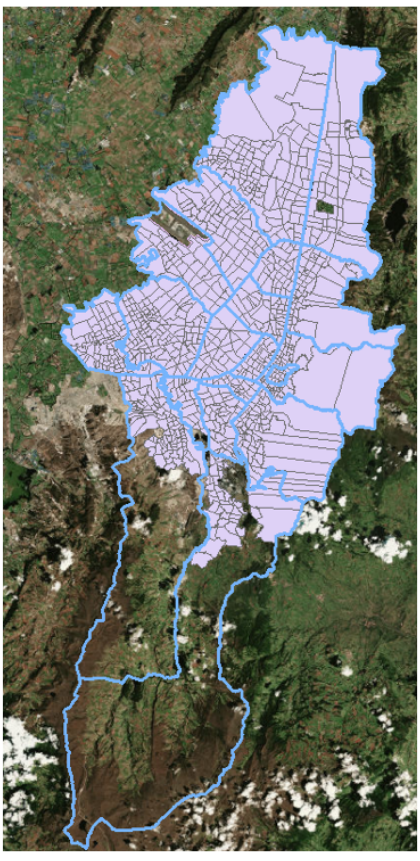

All police quandrants and localities

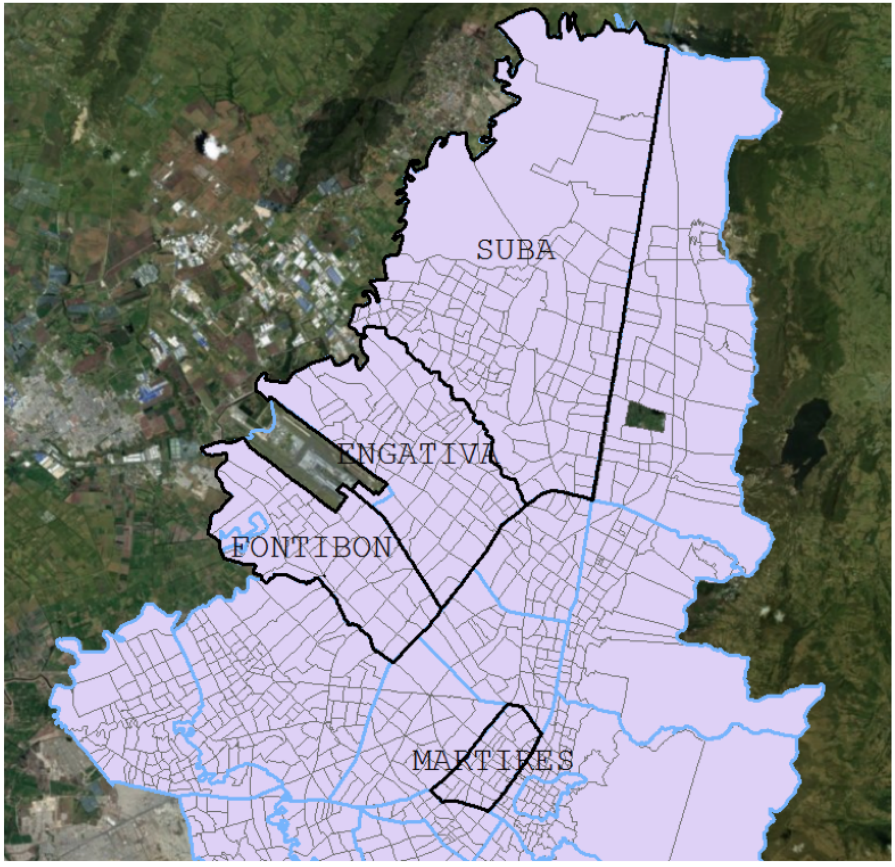

Selected localities

The ethnographic fieldwork provided insights for the design of the intervention, our understanding of the specific problem to be solved, the theoretical account of how the intervention might solve that problem, and the definition of the units for inclusion. On this last point, and following consultations with the Mayor's office, we realized that the city's most dangerous places would be infeasible to include in the intervention, given the need to keep the team safe during repeated visits to treatment and control units. This led us to exclude the most dangerous $10 \%$ of police quadrants, as measured by homicide rates.

In what follows, we describe the data regarding brawls in greater detail, as well as how the sample for the study was constructed. We began by identifying eligible police quadrants and street segments, those with at least one drinking establishment and featuring at least one violent brawl between 2014 and 2017. For this purpose, we merged detailed geographic information from Bavaria's client list and the NUSE database of 
emergency phone calls. ${ }^{6}$ The resulting eligible areas are plotted in Figure 2.

Figure 2. Eligible street segments and police quadrants

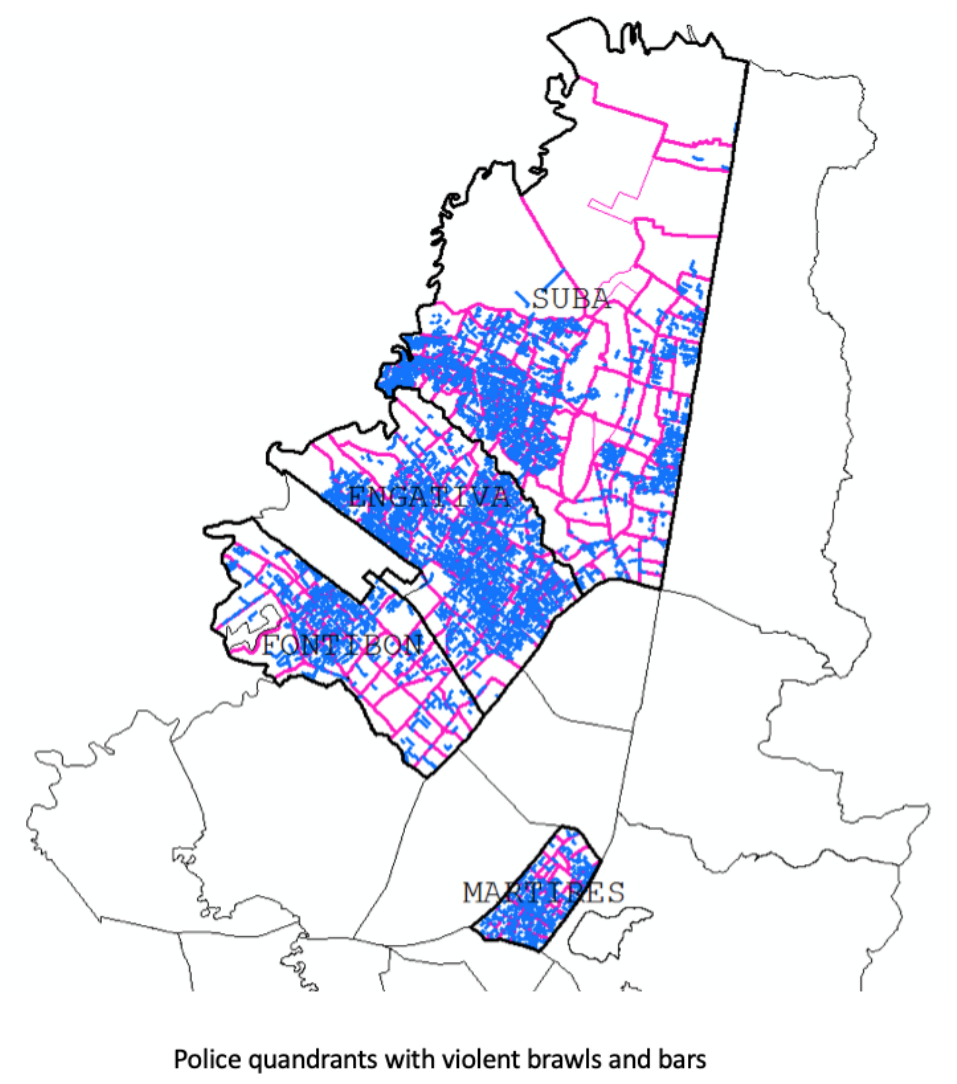

We also carried out a descriptive analysis of violent brawls using data from NUSE, focusing on the four selected neighborhoods or localities. NUSE is operated and coordinated by the Security and Justice Secretariat within the Mayor's Office, which receives all calls made by citizens requesting emergency and security assistance, classifies them according to the emergency, and assigns them to the relevant agencies to address the event. When a person dials 123, the location from which the call is made is saved and, after a coding process, the latitude and longitude of the call is obtained. Additionally, the operator assigned to the call transcribes the conversation and assigns a code according to the incident classification guide used by the Security and Justice Secretariat.

${ }^{6}$ In Colombia, this corresponds to the phone number "123" rather than "911" as in the United States. 
The NUSE code for violent brawls - our outcome of interest - is "934", defined as "any incident or altercation that may arise between two or more people causing physical aggression, which may even lead to endangering someone's life" (SSCJ, 2016, pp. 7). The operator asks if there are any injuries or weapons involved and, if so, transfers the case to the Metropolitan Police (MEBOG) with a high priority flag.

The NUSE database contains information on reports of violent brawls for the entire city, which amounts to around 6 million observations. However, the same event may have more than one entry since multiple calls may report the same incident. Once the database is collapsed by event, there are around 2 million observations for Bogotá. In Table 1 we show the total number of reported violent brawls in the four targeted localities, as well as the percentages for several temporal windows within each locality between January 2014 and February 2018. The data show that the highest percentage of reported violent brawls in this period occurs in Suba (44.4\%), followed by Engativá (34.5\%), which might be due to the fact that these are large localities with many inhabitants. The four targeted localities for this intervention account for $28.3 \%$ of all violent brawls reported in the city during this period. Additionally, there is a similar percentage of violent brawls occurring within each temporal window across localities. In particular, about $50 \%$ of all 123 calls due to violent brawls between January 2014 and February 2018 in each locality occurred between 3:00 pm and 12:00 am. Most brawls occur between 6:00 pm and 12:00 am (approximately 40\%), while around $11 \%$ take place between 12:00 am and 3:00 am. 
Table 1. Number of Violent Brawls by Locality and Temporal Window

\begin{tabular}{cccccc}
\hline & \multicolumn{5}{c}{ Locality } \\
\cline { 2 - 5 } Temporal range & Engativá & Fontibón & Mártires & Suba & Total \\
\hline $03: 00-05: 59$ & $8.0 \%$ & $8.5 \%$ & $6.7 \%$ & $8.5 \%$ & $\mathbf{4 8 , 3 0 1}$ \\
$06: 00-08: 59$ & $7.2 \%$ & $7.0 \%$ & $7.3 \%$ & $7.1 \%$ & $\mathbf{4 2 , 0 7 9}$ \\
$09: 00-11: 59$ & $9.7 \%$ & $9.6 \%$ & $11.3 \%$ & $9.2 \%$ & $\mathbf{5 6 , 2 9 0}$ \\
$12: 00-14: 59$ & $11.6 \%$ & $12.2 \%$ & $15.8 \%$ & $10.5 \%$ & $\mathbf{6 7 , 6 6 5}$ \\
$15: 00-17: 59$ & $11.9 \%$ & $12.5 \%$ & $14.2 \%$ & $11.4 \%$ & $\mathbf{7 0 , 3 0 2}$ \\
$18: 00-20: 59$ & $18.9 \%$ & $19.2 \%$ & $17.2 \%$ & $18.7 \%$ & $\mathbf{1 1 0 , 4 1 7}$ \\
$21: 00-23: 59$ & $21.1 \%$ & $20.0 \%$ & $16.9 \%$ & $21.8 \%$ & $\mathbf{1 2 3 , 5 8 2}$ \\
$00: 00-02: 59$ & $11.7 \%$ & $10.9 \%$ & $10.5 \%$ & $12.8 \%$ & $\mathbf{7 0 , 6 8 9}$ \\
\hline \hline Total & $\mathbf{2 0 3 , 5 6 1}$ & $\mathbf{8 2 , 6 3 6}$ & $\mathbf{4 1 , 5 7 6}$ & $\mathbf{2 6 1 , 5 5 2}$ & $\mathbf{5 8 9 , 3 2 5}$ \\
Percent & $\mathbf{3 4 . 5 \%}$ & $\mathbf{1 4 . 0} \%$ & $\mathbf{7 . 1 \%}$ & $\mathbf{4 4 . 4} \%$ & $\mathbf{1 0 0} \%$ \\
Percent of all Bogotá & $\mathbf{9 . 7 8} \%$ & $\mathbf{3 . 9 7} \%$ & $\mathbf{2 . 0 0} \%$ & $\mathbf{1 2 . 5 6 \%}$ & $\mathbf{2 8 . 3 1 \%}$ \\
\hline \hline
\end{tabular}

Figure 3 shows the distribution of the reported brawls displays in each of the years in this period, and for all four localities. We observe seasonal trends. For example, there are peaks in December and troughs around September. As indicated by the dotted line in the figure, the average number of violent brawls reported to NUSE in these four localities is approximately 12,000 per month.

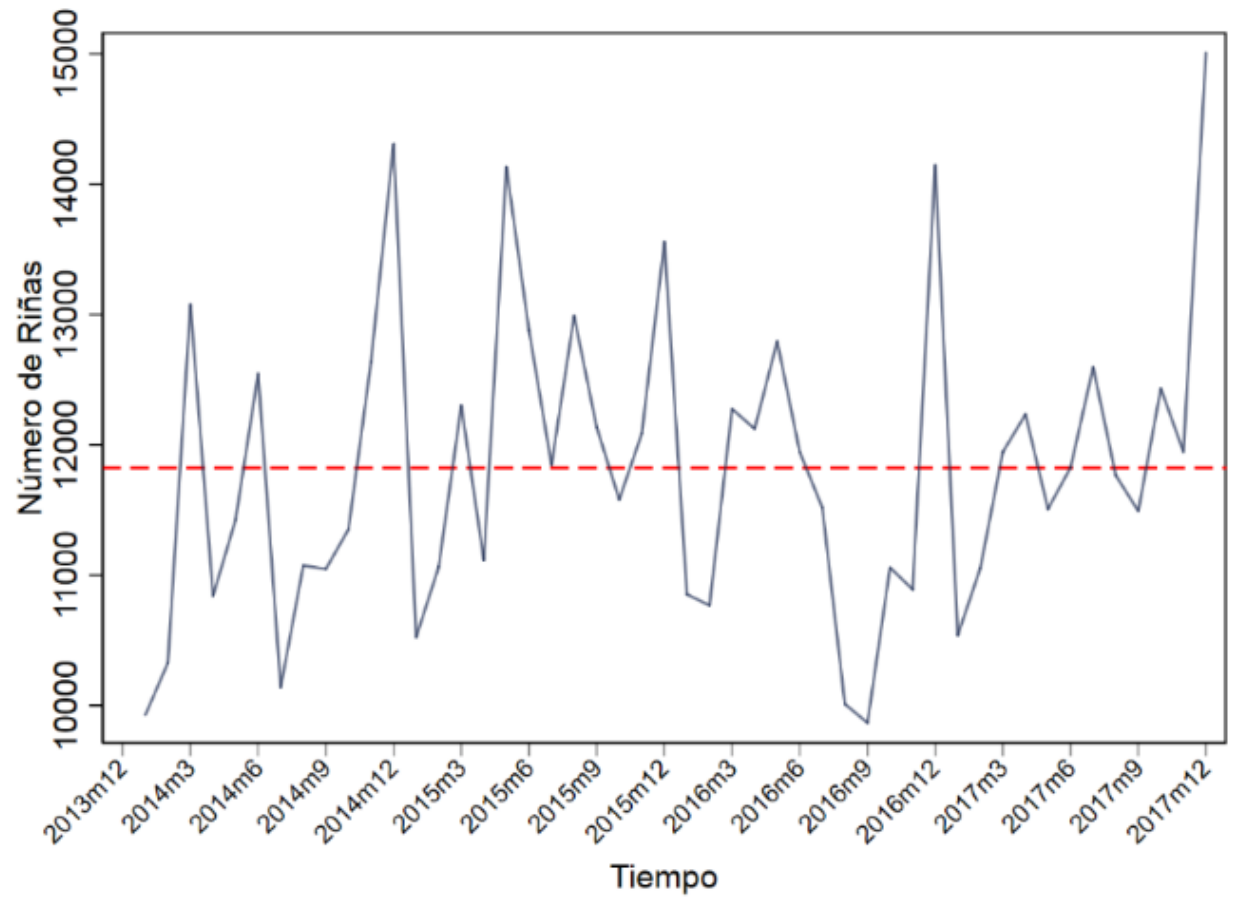

Figure 3. Number of Violent Brawls by Locality and Date

Finally, Figure 4 assesses the distribution of violent brawls by day and time, using 
data from 2017. Calls to NUSE reporting violent brawls often occur in the late afternoon and nighttime, mainly between 6:00 p.m. and 3:00 a.m., and are more likely on weekends.

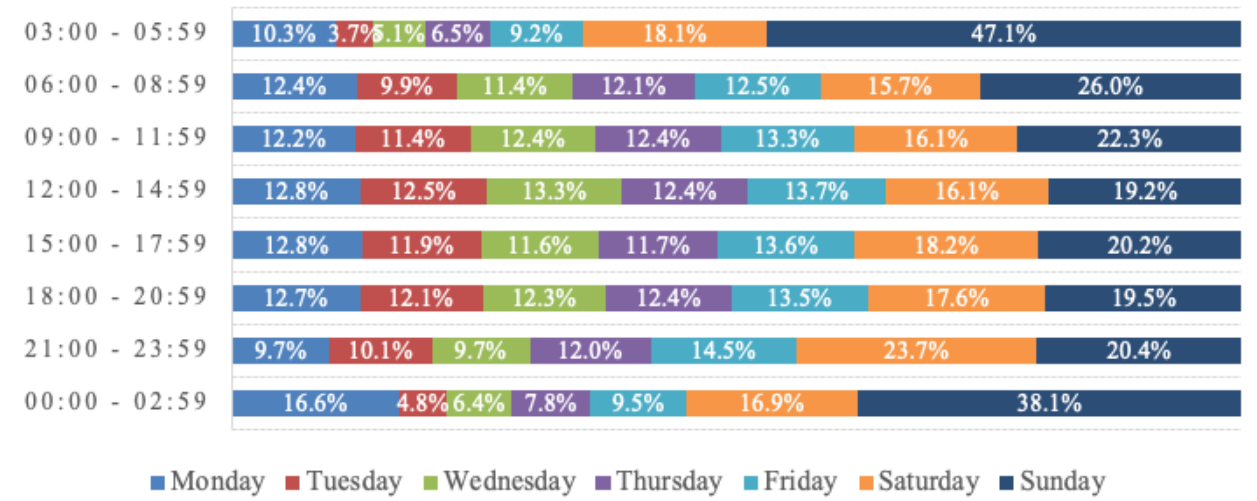

Figure 4. Number of Violent Brawls by Day of the Week and Time

We now turn to the spatial distribution of calls relating to violent brawls in the left panel of Figure 5. Unsurprisingly, we see significant geographic clustering or "hotspots" of violence. Red shading indicates higher intensity of violent brawls, while green indicates relatively fewer violent brawls.

One of the limitations of these data, however, is that it impossible to know if a reported brawl is due to alcohol consumption. We take a first-cut at this by looking at the location of Bavaria's clients, what we have been calling "bars" throughout. The data on bars, provided by Fundación Bavaria, show the location of each store to which alcohol is sold, allowing us to spatially match the location of bars to violent brawls. The database on bars has basic information about the shop and the owner, as well as a category that indicates whether consumption is on-site (i.e., if it has chairs or tables to consume alcohol) or is off-site (i.e., only provides the option to buy and take-away alcohol). One of the limitations of the database is that it can't be known with certainty if alcohol is sold or not, nor can we be sure of the quantities of alcohol sold. The right panel of Figure 5 shows the density of shops in the Bavaria database. In this map, a greater density of shops is indicated by a deeper shade of red. 
Figure 5. Spatial distribution of brawls and bars

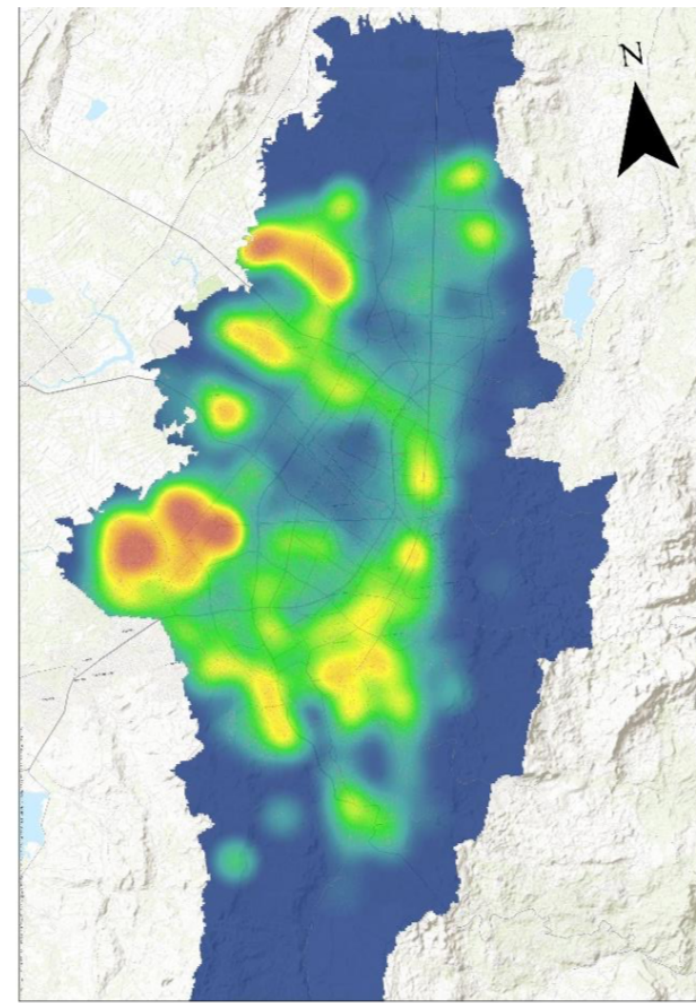

Brawls

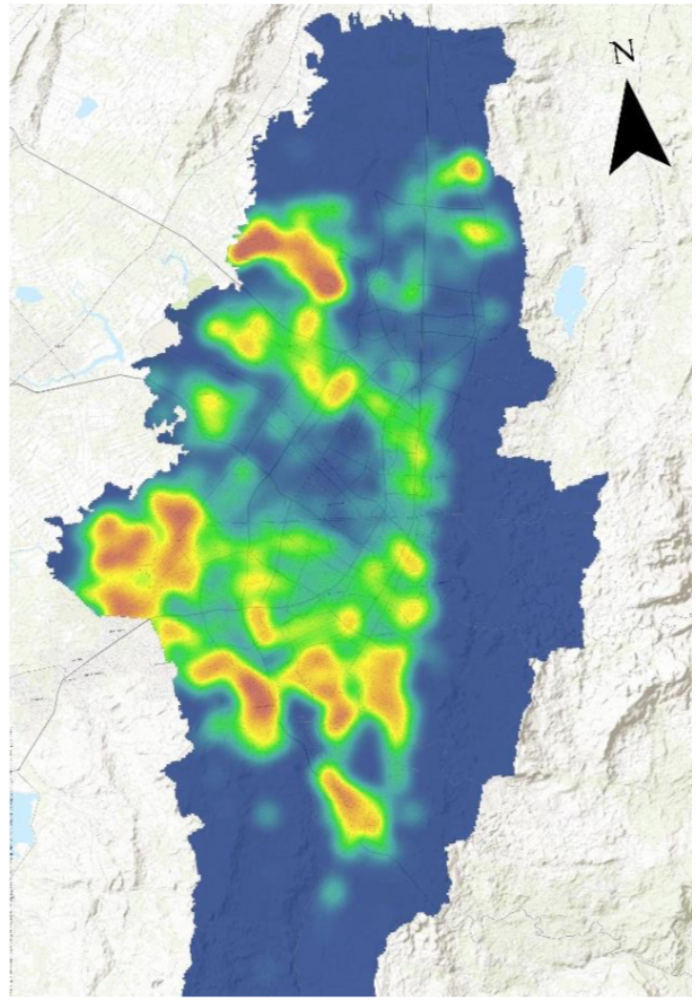

Bars

Although this map provides no evidence of a causal relationship between brawls and the location of bars serving alcohol (or the lack of one), it does indicate some sort of correlation between the geographic concentration of brawls and Bavaria's shops. This may be driven principally by greater commercial activity (and foot traffic) around bars, which helps explain why we see more violent brawls, or it could be the case that overconsumption of alcohol is responsible for this violence. For reference, there is an average of 39.6 shops per police quadrant throughout all of Bogota's 1,051 quadrants.

\section{Randomization}

The randomization consists of two stages. Our universe consists of the four selected neighborhoods or localities in Bogotá. Next, within these localities, we identified eligible 
street segments: those with at least one violent brawl and one bar at a distance equal to or less than 100 meters (see Figure 2$).{ }^{7}$ In the first stage of the randomization, we randomly selected treatment and control police quadrants. Bogotá is composed of 1,051 police quadrants in total. Selection of quadrants therefore occurred in two phases: first, quadrants with at least two pre-selected street segments (given the criteria described above) were chosen. Subsequently, using the Statistical, Criminal, Contravention and Operational Information System (SIEDCO) from the National Police, we discarded the most dangerous decile of quadrants within the four localities. ${ }^{8}$

Table 2. Descriptive statistics, after removing 10\% most dangerous police quadrants

\begin{tabular}{|c|c|c|c|c|c|}
\hline Locality & Police Quadrants & $\begin{array}{l}\text { Street Segments with } \\
\text { Bars and Brawls }\end{array}$ & $\begin{array}{l}\text { Average Street } \\
\text { Seguments per } \\
\text { Quadrant }\end{array}$ & $\begin{array}{c}\text { Average Bars per } \\
\text { Quadrant }\end{array}$ & $\begin{array}{c}\text { Average Bars per } \\
\text { Street Segment }\end{array}$ \\
\hline Engativa & 64 & 2116 & 33.06 & 46.27 & 1.40 \\
\hline Fontibón & 37 & 702 & 18.97 & 28.92 & 1.52 \\
\hline Martires & 21 & 289 & 13.76 & 18.95 & 1.38 \\
\hline Suba & 99 & 2156 & 21.78 & 33.15 & 1.52 \\
\hline Total & 221 & 5263 & 23.81 & 34.89 & 1.47 \\
\hline
\end{tabular}

Across the four localities there are 221 eligible police quadrants in total, 109 were selected into treatment and 112 into the control group. Figure 6 maps these locations.

${ }^{7}$ Given that the intervention was scheduled to begin in August, and because alcohol-related violent brawls are less likely to occur in the morning, violent brawls that occurred between June and September 2017, between the hours of 4:00 pm and 1:00 am, were included.

${ }^{8}$ We assessed different exclusion criteria, including removing the most dangerous $20 \%, 10 \%$, and $5 \%$ of street segments; the mean and standard deviation of violent brawls did not change substantially under these different scenarios, so we opted for the $10 \%$ threshold to maximize statistical power. 
Figure 6. Treatment assignment by Police Quadrants

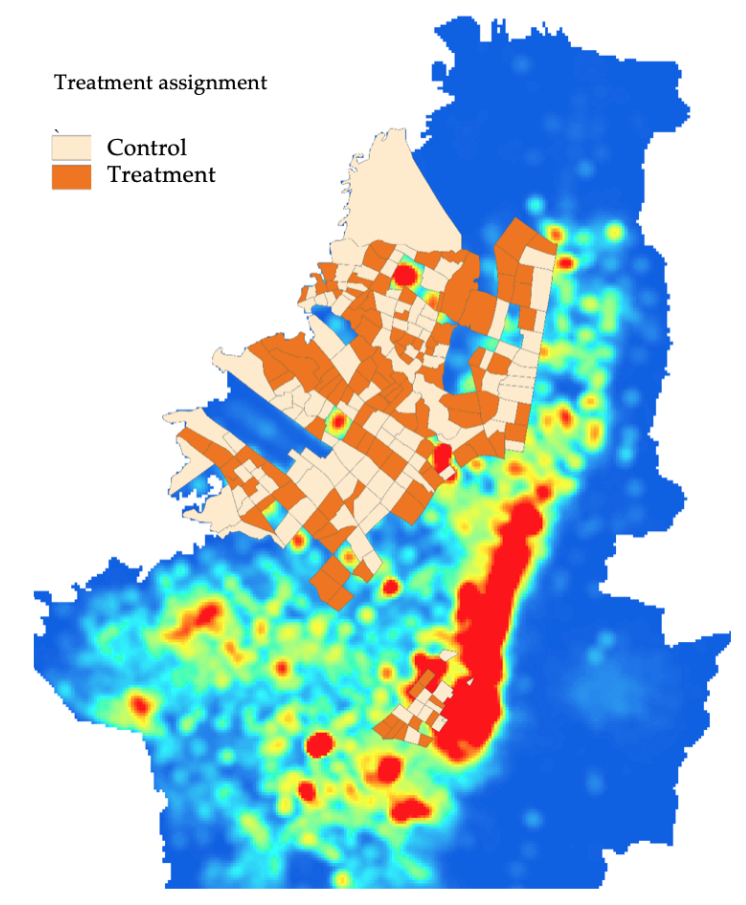

The second stage of the assignment procedure randomly selects street segments within the 109 treated police quadrants to receive the intervention. Given budget constraints that restricted the number of treated bars to 270 , we selected 218 street segments that contained approximately this number of alcohol-serving establishments. Figure 7 maps treated and control street segments within police quadrants by locality, where the purple lines identify treated street segments. We also select street segments in control police quadrants (blue lines) to collect survey data, which we describe in Section 8.

This multi-stage design allows estimating both the direct effects of the intervention, as well as potential spillovers. By comparing outcomes in treated and control street segments, we can estimate the direct impact of the intervention. However, if bar owners in the same police quadrant discuss the intervention amongst themselves, then our estimates of the treatment effect would be contaminated. To avoid such issues, we also compare street segments across treated and control police quadrants. Since no street seg- 
ments in control police quadrants will receive the intervention, these locations constitute a "pure" control group that allows isolating any potential spillover effects. As such, our sample includes: treated street segments located within treated police quadrants; untreated street segments located within treated police quadrants; and untreated street segments located within untreated police quadrants ("pure control" street segments).

Figure 7. Treatment assignment by Street Segments

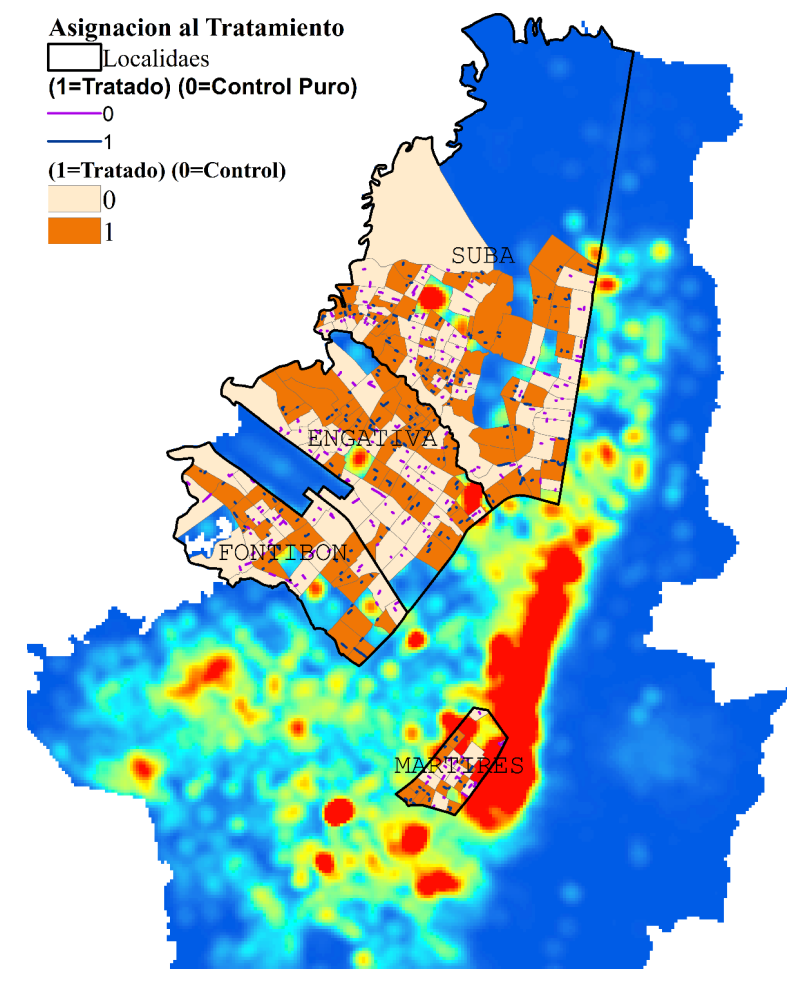

Using data on reported brawls from previous years, we are able to calculate statistical power for both direct and spillover effects. At the level of police quadrants (spillover) we can observe a minimum detectable effect of 0.30 standard deviations in violent brawls. These calculations were made given 221 police quadrants, approximately 23.81 street segments per quadrant, an estimated mean of 16.16 brawls, standard deviation of 12.06, and an intra-cluster correlation estimate of o.24. Figure 8 shows the minimum detectable effect (MDE) with $80 \%$ power and how the MDE falls with a higher $R^{2}$ coefficient. 
Figure 8. Statistical Power at the Police Quadrant Level

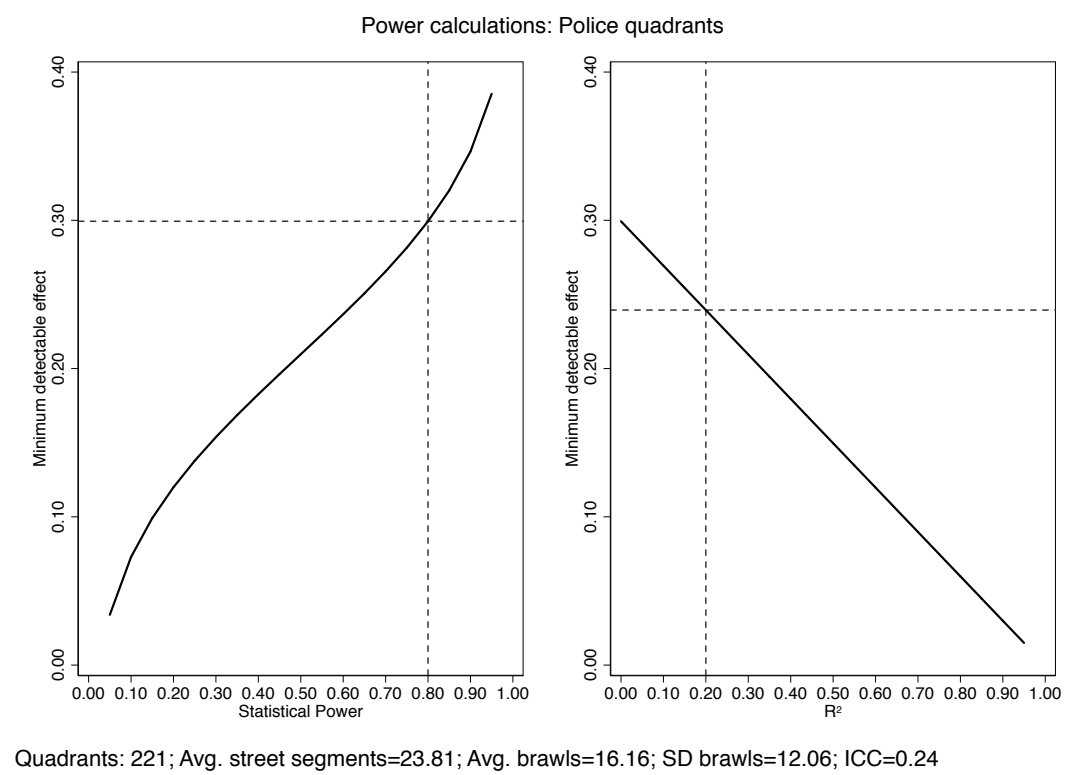

At the level of street segment, we are powered at $80 \%$ to detect a change of 0.27 standard deviations in brawls. These calculations were made given 2,539 street segments; 1.57 bars per segment; an estimated mean of 3.57 brawls; standard deviation of 3.19; and intra-cluster correlation of 0.20. As before, we summarize the results in Figure 9.

Figure 9. Statistical Power at the Street Segment Level

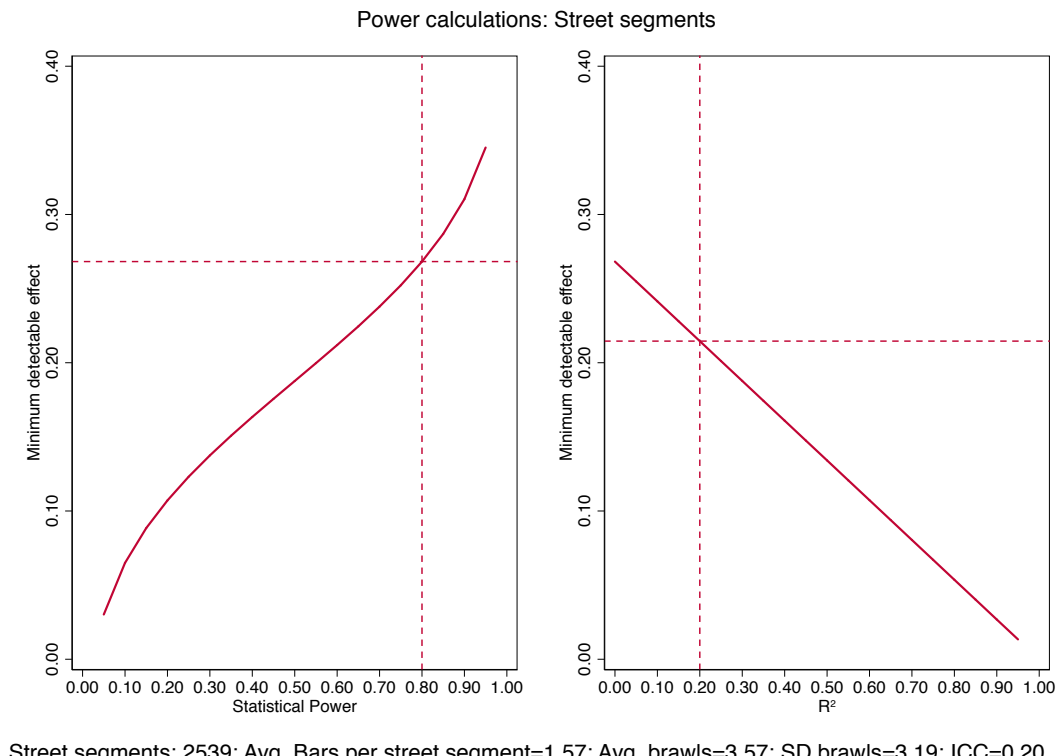




\section{Intervention}

This project explores an innovative and scalable intervention. We provide didactic materials to bar patrons and offer food and non-alcoholic drinks to bar patrons with two primary objectives: reducing the negative consequences frequently associated with the rapid, overconsumption of alcohol, and defusing conflictual dynamics between bartenders and patrons, and among patrons that might escalate to produce violent brawls both within and immediately around bars. The intervention is designed to be scalable both to other neighborhoods in Bogotá and other cities in Colombia or other countries where violent brawls and alcohol intake are widespread. The intervention consists of four steps.

\subsection{Contact/registration}

Initial contact with bars located on street segments in the treatment group is made. The intervention team discusses the general idea of the program and asks the bartender(s) if they would like to participate. If they refuse, no further time is taken from these individuals. If they accept, the team walks through the intervention strategy with the bartender(s) and receives contact information for the bartender(s).

For bars that accept, the team also provides a brief explanation of the "Good Bartender" manual and a "Good Bartender" kit that includes a custom-made welcome mat emblazoned with the words: "Welcome to an establishment that promotes 'safe shots' 9 and the logo of the intervention; a sticker, to be affixed to the window of the bar, with the logo of the intervention along with the slogan "Enjoy calmly - this is an establishment where the night always ends well"10; a clock that reminds patrons that 11:0opm is "last call"; and a water jug with the logo of the intervention and the slogan "If you feel things

9"Bienvenido a uno de los establecimientos que promueve los buenos tragos".

10"Disfrute con tranquilidad. Este es un establecimiento donde la noche siempre termina bien". 
are burning up [slang for getting drunk], extinguish with water."11

Figure 10 shows images of some of the items described above, produced by an advertising agency in Bogotá to capture the attention of bartenders and patrons.

Figure 10. Materials given to participating bars

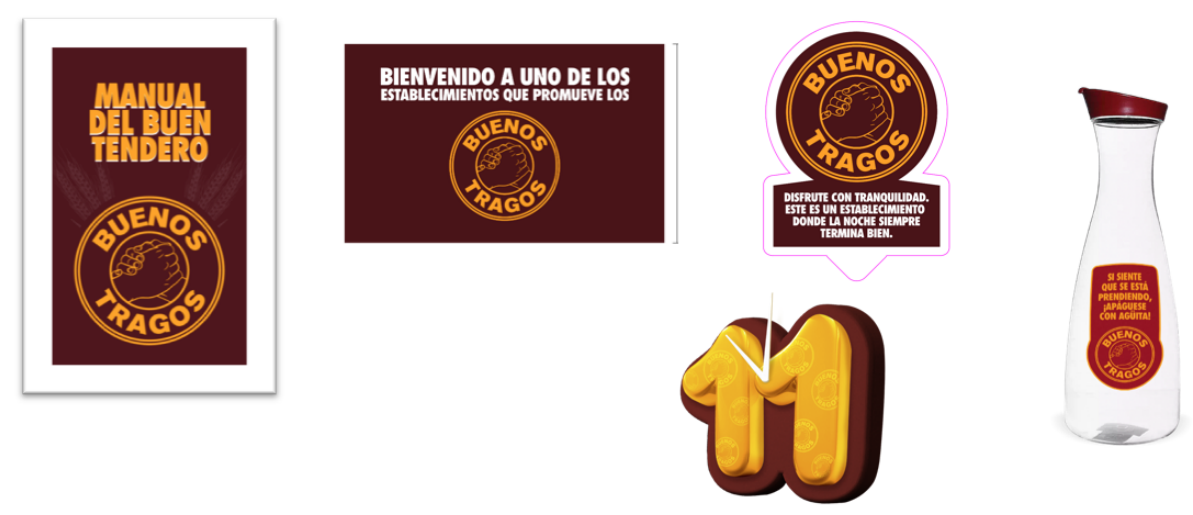

\subsection{Activation within the bar}

On a Thursday, Friday or Saturday night, between the hours of $6 \mathrm{pm}$ and $11 \mathrm{pm}$, team members arrive at bars located on treated street segments and offer a round of food to all those at the bar who are consuming alcohol, while also ensuring that customers have access to water, served from jars with the logo of the intervention. Team members also remind bartenders how to put into action the tips from the Good Bartenders manual and provide coasters with the logo of the intervention for use by patrons. A sticker is placed on the wall of the bar that indicates that the bar is participating in the program. Finally, the bartender is told that in the coming weeks a "mystery shopper" will enter the bar to assess whether the basic tenets of the intervention remain in place.

\subsection{Follow-up and data collection}

The follow-up and monitoring phase has two components. First, there will be two visits by a "mystery shopper" in each drinking establishment to evaluate the extent to 11"Si se siente que se está prendiendo, apáguese con aguita". 
which the bartender is practicing the lessons learned during the intervention. If the bar is deemed to be in compliance with the principles of the intervention, the "mystery shopper" distributes raffle tickets to win a jukebox. Two jukeboxes per locality - eight in total - will be distributed to the winners. Second, once the intervention concludes a survey firm will visit bars in treated segments and quadrants, as well as bars in untreated segments in untreated quadrants to gather additional information on the bar, its patrons, and other information of interest. Survey respondents were given raffle tickets to participate in the lottery for a $32^{\prime \prime}$ flat screen television. Figure 11 shows the cumulative number of bars that will be visited for data collection per week.

Figure 11

\begin{tabular}{llll} 
November 5-9, 2018 & November 12-16, 2018 & November 19-23, 2018 & November 26-30, 2018 \\
\hline 160 & 320 & 500 & 540
\end{tabular}

\subsection{Recognition}

Once the intervention ends and survey data have been collected in both treatment and control bars, the locality that has seen the largest decrease in violent brawls during the study period will be recognized via a public campaign in which a well-known DJ will travel thorough the streets, interacting with participating bartenders. Winners of the raffle will be awarded their jukeboxes in a public event with the relevant authorities.

\section{Theoretical framework and hypotheses}

Our study begins from the intuition that bartenders can be crucial levers for defusing tense and potentially violent situations among patrons; that continual, uninterrupted consumption of alcohol without sufficient food or non-alcoholic drink offerings can result in belligerent behavior among some bar clients; and that the absence of a welcoming, safe environment for the consumption of alcohol may help induce patrons to engage in violent behavior in and around bars. While some evidence exists on the role of self- 
control in alcohol consumption (Schilbach, 2019), there is less evidence on the impact of bartenders and the drinking environment in modifying the level of alcohol consumption, water, food, and other outcomes such as violent events.

The intervention we evaluate is designed to address a number of challenges that link excessive alcohol consumption in bars to violent brawls, which we describe in turn.

\section{Lack of knowledge among bartenders about how to handle unruly patrons and defuse}

disputes. The vast majority of bartenders have no formal training in how to manage situations that might escalate to violence. In our particular Latin American context, "bartenders" are simply the owners of the establishments where alcohol is served.

Insufficient food or non-alcoholic drink options in bars that could help lessen the negative consequences of excessive and rapid alcohol consumption. Owners of bars and stores that sell alcohol may not have sufficient incentives to offer water or other non-alcohol drinks due to a host of factors. Relatedly, they may not have sufficient infrastructure or space (e.g. a deep fryer for serving local "bar" food, a food prep area, or sufficient space in the refrigerator for food) to offer options for sustenance that might help diminish the potentially negative consequences of excessive alcohol intake.

Insufficient understanding among bar patrons about the risks of excessive alcohol consumption and the risks of dispute escalation. Few patrons understand what overconsumption involves and how quickly disputes can escalate when one is under the influence of alcohol. The climate within the bar may be a relevant factor that heightens or lessens the likelihood of violence among patrons.

Taken together, these challenges produce undesirable interactions among bar patrons, bartenders, and state authorities charged with keeping the peace in neighborhoods where alcohol consumption occurs in commercial establishments. 
The intervention we evaluate is designed to address each of these challenges. It aims to educate bartenders about what it means to be a "good" bartender, via in-person training and a take-home manual. We also provide incentives for bartenders to continually implement the lessons learned from this training and the manual. In so doing, we hope to better understand the role of bartenders in regulating clients' behavior, both within and beyond the sites where alcohol is sold and consumed. As previously mentioned, less work has been done on this front, and we believe that this is a fruitful way forward to empower a crucial community figure in spaces where violence frequently originates. We also target bar patrons via humorous yet pedagogically-useful materials that remind them of the need to drink water and eat food while consuming alcohol.

Unlike most existing studies, our experimental evaluation allows for more precise estimates of causal effects regarding how to reduce violence caused by excessive alcohol consumption. Additionally, as noted above, we target a population (bartenders) that have been understudied and that we contend can be leveraged to produce social change. Finally, we have forged a unique partnership between the private and public sector that we believe could be replicated elsewhere to maximize program effectiveness.

We will test four primary hypotheses:

H1: Treated street segments located within treated police quadrants will experience fewer violent brawls than either untreated street segments located within treated police quadrants or untreated street segments located within untreated police quadrants.

H2: The intervention will not displace violent brawls toward street segments geographically close to treated street segments.

$\mathbf{H}_{3}$ : The intervention will produce the largest effects on treated street segments where sales of water and food in bars have increased the most.

$\mathbf{H}_{4}$ : The intervention will not change alcohol sales. 


\section{Data}

We will employ two sources of data for the evaluation: i) administrative records on brawls in and around bars and ii) survey data for bars collected after the intervention.

The administrative data consists of brawl reports from 2014 onward collected by the Security and Justice Secretariat of the city of Bogotá, which we have referred to as the NUSE database. We will also use records from the Statistical, Criminal, Contravention and Operational Information System (SIEDCO) from the National Police that measure other violent events in the city. Merged with client records from Bavaria, we can measure reported brawls in and around the street segments where the bar is located, given that both sources are geocoded. These data will provide measures for a number of primary outcomes: 1) violent brawls per police quadrant; 2) violent brawls per street segment; and 3) other violent events in both street segments and police quadrants in Bogotá.

A survey instrument was designed to measure the mechanisms that could drive potential changes in reported brawls, including a) the value of all alcohol sold in different temporal windows, b) the value of water sold in different temporal windows; and c) the value of food sold in different windows. Via this endline survey instrument, we will gather data on the bar (e.g. years of operation; hours of operation; whether it has a bathroom for clients; how many tables and chairs; whether private security is provided; the kind of alcohol served; whether non-alcoholic beverage options are available; the kinds of food served; sales of alcohol in recent months; sales of water in recent months; and sales of food in recent months), the bartender (e.g. whether s/he is the owner, whether $\mathrm{s} /$ he lives in the neighborhood, education level, number of years as a bartender), and the characteristics of the clientele (regulars or not; gender; age; number of clients during the previous weekend; whether clients pay after each drink or accumulate a "tab"). We also 
will ask bartenders about the frequency of disagreements within their bars, how these disagreements are resolved, and pose a series of scenarios related to the potential causes of violent brawls and how bartenders would resolve them.

The survey will also collect data on the surroundings of the bars, including: the level of cleanliness of the street segment; the quality of the pavement in the street segment; whether there are sidewalks on the street segment; whether the bar is located on a street corner; whether the street segment is principally residential; whether there are other commercial establishments on the street segment (and if so, of what kind); and whether there are street vendors on the street segment.

\section{Estimation strategy}

Given the administrative data that are available to us, we will estimate the effects of the intervention on brawls using a difference-in-differences specification:

$$
y_{s q t}=\alpha+\beta_{1} D_{s t}^{1}+\beta_{2} D_{q t}^{2}+\gamma X_{s q t}+\lambda_{s}+\delta_{t}+u_{s q t}
$$

where $s$ refers to street segments, $q$ to police quadrants, and $t$ indexes time (week-year or month-year cells). For instance, we will use the number of brawls in street segment $s$ in police quadrant $q$ during week-year $t$ as our dependent variable. We will estimate two treatment effects. First, $\beta_{1}$ captures the difference between treated and control street segments before and after the program within treated police quadrants. Second, $\beta_{2}$ captures potential spillover effects of the intervention across treated and control police quadrants over time. ${ }^{12}$ Standard errors will be clustered by street segment and police quadrant.

If the data allow, we will include time-varying controls at the street segment and/or police quadrant level. Additionally, we will include time-invariant fixed effects as the

${ }^{12}$ The attached variables on these coefficients, $D_{s t}^{1}$ and $D_{q t}^{2}$, are interactions between treatment indicators $\left(T_{s}^{1}\right.$ and $\left.T_{q}^{2}\right)$ and a variable equal to one after the program begins (Post). 
data permits (e.g. neighborhood or locality, police quadrant, or street segment), as well as time effects to control for secular trends in brawls over the period of study.

This main specification estimates the intent-to-treat effects of the intervention on our selected outcomes. As we discuss below, the interpretation of the coefficients depends on the level of compliance with the intervention. This may affect our estimates because we may need to account for non-compliance with the intervention by means of a twostage procedure. If random assignment differs from effective treatment, we will employ instrumental variable methods to estimate a Local Average Treatment Effect (LATE) on compliers (Angrist et al., 1996). In this scenario, we could also consider different probability weighting schemes that help capture effective exposure to the intervention.

Given that survey data will only be available after the treatment has taken place, we will study the effects of the intervention using a cross-section post specification:

$$
y_{i s}=\alpha+\beta T_{s}^{1}+\gamma X_{i s}+\varepsilon_{i s}
$$

where $i$ refers to a bar and $s$ its street segment. Note that unlike the previous strategy, we are unable to isolate direct and indirect effects. The $\beta$ coefficient captures mean differences between bars in treatment and control street segments after the program. The outcomes measured using this regression will mostly shed light on the mechanisms that explain any observed changes in violence around these alcohol-serving establishments. For instance, we will compare average sales of alcohol, water, and food between treatment and control bars. We will include establishment-level controls and fixed effects by neighborhood or locality. Standard errors will be clustered at the street segment level. As in the case with administrative data, these estimates capture the intent-to-treat effects of the "Good Bartenders" intervention. If we need to correct our estimates to account for differential compliance, we will proceed as mentioned in the previous sub-section. 
As an extension to the main estimation strategy using administrative and survey data, we will estimate heterogeneous treatment effects. For example, we would like to test whether the intervention has a differential effect by neighborhood or locality, whether the effect varies over time, and other location-level attributes (that include but are not limited to socioeconomic status and previous history of violence). Since the survey data contain a rich set of attributes for alcohol-serving establishments, we will also test whether certain bars changed their behavior more than others due to the intervention.

Finally, we will adjust the estimated p-values for the coefficients of interest given that we use multiple outcomes using the same source of variation. Some possibilities include adjusting for the false discovery rate (Benjamini and Hochberg, 1995) and randomization inference (Imbens and Wooldridge, 2009). These methods, which are becoming more widely used in social sciences, will increase the transparency of our results and lend support that any effects we find are due to the intervention and not chance findings.

\section{Threats to inference}

The main threat to our identification strategy is non-compliance. This non-compliance can take several forms. On the one hand, treated bars may receive the treatment but not put it into practice. To avoid these problems, the intervention contemplated two visits from "mystery shoppers" and maintained an incentive scheme that lasted for approximately two months after the intervention ends. By using data from these visits, we could adjust our estimates to capture different treatment intensity across bars.

On the other hand, the other form of non-compliance has to do with refusal from some bars to participate in the program. As mentioned in Section 4, randomization took place first at the quadrant-level and then at the street segment-level. In the latter case, more than one bar can be located on a given street segment. Due to logistical reasons, the research team opted to follow a standard procedure to deal with refusals. If all bars 
in a treated street segment refused to participate, then a new street segment is randomly selected as a replacement. If at least one bar in a treated street segment participates but others refuse, we keep that street segment in our sample. If all bars in a treated street segment participate, we keep that street segment. Therefore, some street segments receive more treatment than others. Once the data are available we can estimate the extent of this form of non-compliance and, if necessary, adjust our empirical strategy to account for different treatment intensity across street segments (our unit of observation).

Other potential challenges in our evaluation relate to bar closings, change of addresses; and ownership changes, all of which are beyond our control. First, bars tend to open and close rapidly, responding to changes in the economic cycle. If bars close shortly after the intervention, the treatment will not have effectively taken place. We will work with our partners to get precise measures of whether bars on street segments in our sample remain open or have closed. Second, some bars become restaurants or establishments that do not serve alcohol. The result for our evaluation is the same as the case with bar closings. Similar to that case, we will attempt to closely monitor any changes in the nature of these establishments. Last, a bar could change owners, and the new owner may not have received information about the intervention from the previous owner. With help from Bavaria, we can try to monitor such changes in our sample and adjust accordingly.

\section{Conclusion}

This Pre-Analysis Plan presents the "Good Bartender" intervention, including the context of the intervention, its randomized design, evaluation strategy, and potential caveats. This pilot intervention is directed at bartenders in four neighborhoods or localities in Bogotá, Colombia. Its goal is to determine whether alcohol-induced violent brawls can be reduced via a low-cost, scalable intervention undertaken through a public-private part- 
nership. ${ }^{13}$ Its objectives are to empower bartenders, provide didactic materials to bar patrons, and offer food and non-alcoholic drinks to bar patrons to reduce violent brawls.

${ }^{13}$ The intervention has been designed by Bogotá's mayor's office, Colombia's largest brewery (Bavaria), and the team of researchers. 


\section{References}

Abt, T. P. (2017). Towards a framework for preventing community violence among youth. Psychology, health $\mathcal{E}$ medicine, 22(sup1):266-285.

Anderson, D. M., Crost, B., and Rees, D. I. (2016). Wet laws, drinking establishments and violent crime. The Economic Journal.

Angrist, J. D., Imbens, G. W., and Rubin, D. B. (1996). Identification of causal effects using instrumental variables. Journal of the American statistical Association, 91(434):444-455.

Benjamini, Y. and Hochberg, Y. (1995). Controlling the false discovery rate: a practical and powerful approach to multiple testing. Journal of the royal statistical society. Series $B$ (Methodological), pages 289-300.

Blattman, C., Green, D., Ortega, D., and Tobón, S. (2017). State building in the city: The effects of public security and services on crime, violence and state legitimacy in Bogotá. Unpublished manuscript.

Graham, K. and Livingston, M. (2011). The relationship between alcohol and violence: population, contextual and individual research approaches. Drug and Alcohol review, 30(5):453-457.

Griswold, M. G., Fullman, N., Hawley, C., Arian, N., Zimsen, S. R., Tymeson, H. D., Venkateswaran, V., Tapp, A. D., Forouzanfar, M. H., Salama, J. S., et al. (2018). Alcohol use and burden for 195 countries and territories, 1990-2016: a systematic analysis for the global burden of disease study 2016. The Lancet, 392(10152):1015-1035.

Grönqvist, H. and Niknami, S. (2014). Alcohol availability and crime: Lessons from liberalized weekend sales restrictions. Journal of Urban Economics, 81:77-84.

Heaton, P. (2012). Sunday liquor laws and crime. Journal of Public Economics, 96(1):42-52.

Imbens, G. W. and Wooldridge, J. M. (2009). Recent developments in the econometrics of program evaluation. Journal of Economic Literature, 47(1):5-86.

Lovenheim, M. F. and Steefel, D. P. (2011). Do blue laws save lives? the effect of sunday alcohol sales bans on fatal vehicle accidents. Journal of Policy Analysis and Management, $30(4): 798-820$.

Marcus, J. and Siedler, T. (2015). Reducing binge drinking? the effect of a ban on latenight off-premise alcohol sales on alcohol-related hospital stays in germany. Journal of Public Economics, 123:55-77.

Pridemore, W. A. and Snowden, A. J. (2009). Reduction in suicide mortality following a new national alcohol policy in slovenia: An interrupted time-series analysis. American journal of public health, 99(5):915-920. 
Room, R., Jernigan, D., Carlini-Marlatt, B., Gureje, O., Mäkelä, K., Marshall, M., MedinaMora, M. E., Monteiro, M., Parry, C., Partanen, J., et al. (2002). Alcohol in developing societies: a public health approach. Finnish Foundation for Alcohol Studies.

Rossow, I. (2001). Alcohol and homicide: a cross-cultural comparison of the relationship in 14 european countries. Addiction, 96(1S1):77-92.

Schilbach, F. (2019). Alcohol and Self-Control: A Field Experiment in India. American Economic Review: Forthcoming.

Sher, L. (2005). Alcohol consumption and suicide. Qjm, 99(1):57-61. 